\section{Device to Detect Blossom End Defects in Papaya Fruit}

\author{
Harvey T. Chan, Jr., Myles H. Taniguchi, and Edward S. Linse \\ Tropical Fruit and Vegetable Research Laboratory, U.S. Department of \\ Agriculture, Agricultural Research Service, P. O. Box 4459, Hilo, \\ HI 96720
}

Additional index words. Carica papaya, Dacus dorsalis, double-dip hot water treatment, navel, pinhole, quarantine treatment

Blossom end defects have been found to be responsible for the presence of Oriental fruit fly larvae (Dacus dorsalis Hendel) in papaya (Carica papaya L.) after hot water double-dip quarantine treatment in Hawaii. The two types of blossom end defects, navel and pinhole, responsible for the quarantine failure were the result of abnormal placental growth near the blossom end of the fruit (Zee et al., 1989). As part of the quarantine procedure, papayas with navel and pinhole defects are routinely culled out of the packing line by trained personnel. The culling procedure for pinhole defects is especially tedious, requiring close visual inspection with the aid of a magnifying lens. In addition, many sound fruits are misclassified and culled out due to the lack of nondestructive testing devices.

We have devised and tested a prototype device to confirm the presence of blossom end defects in papayas. The detection of defective papayas with an open stylar end is based on the premise that normal papayas with closed or fused stylar ends will resist any change in applied positive or negative pressures. In contrast, blossom end defective papayas with open stylar ends have an open

Received for publication 27 July 1989. The cost of publishing this paper was defrayed in part by the payment of page charges. Under postal regulations, this paper therefore must be hereby marked advertisement solely to indicate this fact. channel to the internal seed cavity that characteristically has a void volume of $4.9 \pm$ $1.9 \mathrm{ml}$.

To create the negative pressure, a simple detection device was constructed using a syringe $(20 \mathrm{cc})$ that was connected to a molded rubber cup upon which a rubber foam gasket was bonded (Fig. 1). Papayas were firmly placed on the rubber gasket. The syringe plunger was withdrawn and the vacuum measured. If the papaya had a closed stylar end, a vacuum of at least $254 \mathrm{~mm} \mathrm{Hg}$ was attained, accompanied by the return of the syringe plunger to its original position upon its release. If the papaya had an open stylar

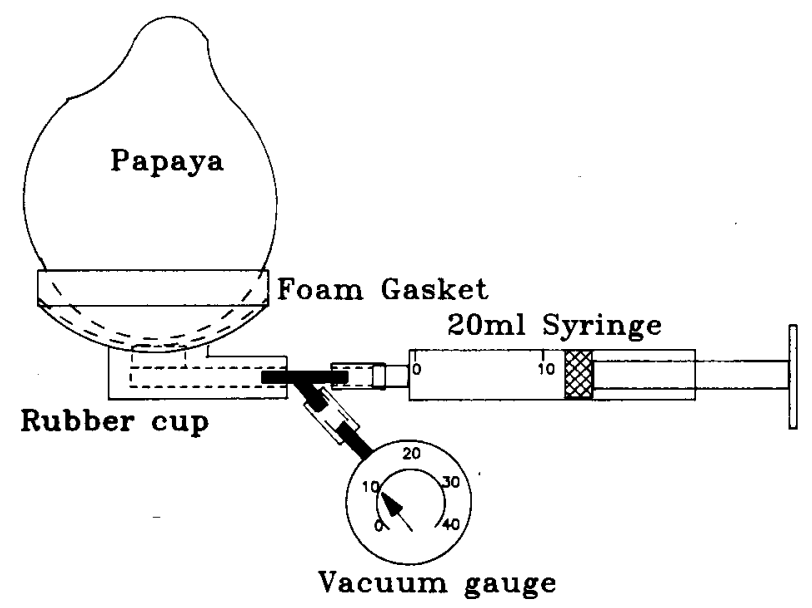

Fig. 1. A device to detect open stylar ends (pinholes) in papaya fruits. end, a vacuum of $<254 \mathrm{~mm} \mathrm{Hg}$ was created, and the syringe plunger would not return to its original position.

We tested 57 papayas that had been culled from a commercial packinghouse that were suspected of having pinhole defects. Using our blossom-end defect testing device, we detected 12 fruits with true pinholes or open stylar ends. Dissection of all 57 fruits confirmed the presence of pinholes in all of the 12 fruits that were sorted out with the blossom-end defect testing device. Dissection also confirmed the absence of open stylar ends in fruit judged to be sound by our testing device.

Using this simple prototype device, we showed that $79 \%$ of the papayas were misclassified as having pinholes and thus can be salvaged due to the nondestructive nature of our testing_ device. Besides being accurate and simple, this testing device has the potential for development into a fully automated production model.

\section{Literature Cited}

Zee, F. T., M.S. Nishina, H.T. Chan, Jr., and K.A. Nishijima. 1989. Blossom end defects and fruit fly infestation in papayas following hot water quarantine treatment. HortScience 24:323-325. 